\title{
Article
}

\section{A Mechanistic Study on the Formation of Dronic Acids}

\author{
Péter Ábrányi-Balogh ${ }^{1, *}$, István Greiner ${ }^{2} \mathbb{B}$ and György Keglevich ${ }^{3, *} \mathbb{C}$ \\ 1 Research Centre for Natural Sciences, Medicinal Chemistry Research Group, 1117 Budapest, Hungary \\ 2 Gedeon Richter Plc., 1475 Budapest, Hungary; i.greiner@richter.hu \\ 3 Department of Organic Chemistry and Technology, Budapest University of Technology and Economics, \\ 1521 Budapest, Hungary \\ * Correspondence: abranyi-balogh.peter@ttk.mta.hu (P.Á.-B.); keglevich.gyorgy@vbk.bme.hu (G.K.); \\ Tel.: +36-1-463-1111 (ext. 5883) (G.K.)
}

\section{check for}

updates

Citation: Ábrányi-Balogh, P.; Greiner, I.; Keglevich, G. A Mechanistic Study on the Formation of Dronic Acids. Molecules 2021, 26, 7587. https:// doi.org/10.3390/molecules26247587

Academic Editor: Evgueni Kirillov

Received: 22 November 2021

Accepted: 9 December 2021

Published: 14 December 2021

Publisher's Note: MDPI stays neutral with regard to jurisdictional claims in published maps and institutional affiliations.

Copyright: (c) 2021 by the authors. Licensee MDPI, Basel, Switzerland. This article is an open access article distributed under the terms and conditions of the Creative Commons Attribution (CC BY) license (https:// creativecommons.org/licenses/by/ $4.0 /)$.

\begin{abstract}
Dronic acid derivatives, important drugs against bone diseases, may be synthesized from the corresponding substituted acetic acid either by reaction with phosphorus trichloride in methanesulfonic acid as the solvent or by using also phosphorous acid as the P-reactant if sulfolane is applied as the medium. The energetics of the two protocols were evaluated by high-level quantum chemical calculations on the formation of fenidronic acid and benzidronic acid. The second option, involving $(\mathrm{HO})_{2} \mathrm{P}-\mathrm{O}-\mathrm{PCl}_{2}$ as the nucleophile, was found to be more favorable over the first variation, comprising $\mathrm{Cl}_{2} \mathrm{P}-\mathrm{O}-\mathrm{SO}_{2} \mathrm{Me}$ as the real reagent, especially for the case of benzidronate.
\end{abstract}

Keywords: dronic acid; carboxylic acid; phosphorus trichloride; phosphorous acid; solvents; mechanism; calculations

\section{Introduction}

Hydroxymethylenebisphosphonic (dronic) acid derivatives include important representatives that are used in the treatment of bone illnesses, such as osteoporosis, the Paget disease, and tumor-induced hypercalcemia [1-4]. The first-generation agents (etidronate, clodronate, and tiludronate) were only moderately potent, allowing a narrow therapeutic window regarding the desired inhibition and impairment of bone mineralization. Hence, they were replaced by second-generation ( $N$-aliphatic) drugs, such as pamidronate, alendronate, and ibandronate [5-7], and third-generation ( $N$-heterocyclic) species, such as risedronate and zoledronate, in clinical use $[8,9]$. The most important derivatives are shown in Figure 1.

The general method for the synthesis of dronic acid derivatives involves the reaction of the corresponding substituted acetic acid with phosphorus trichloride $\left(\mathrm{PCl}_{3}\right)$ or with $\mathrm{PCl}_{3}$ and phosphorous acid $\left(\mathrm{P}(\mathrm{OH})_{3}\right)$ in different solvents. The optimum conditions (molar ratios, solvent, temperature, and reaction time) as well as the role of the reagents and the mechanism were not described. Moreover, the purity of the products was not clarified and hence misleading yields were published. Keglevich, Grün, and Greiner, together with co-workers, investigated the chemistry of dronic derivatives in detail [4]. The optimum conditions were explored on the basis of the putative mechanisms substantiated by us [10]. According to this, for carrying out the reactions in methanesulfonic acid (MSA), there was the need for 3-3.2 equivalents of the $\mathrm{PCl}_{3}$. It was assumed that 1 equivalent of the $\mathrm{PCl}_{3}$ converts the substituted acetic acid to the corresponding chloride, while 2 equivalents are needed to provide the two P-functions. Both $\mathrm{PCl}_{3}$ and $\mathrm{Cl}_{2} \mathrm{P}-\mathrm{O}-\mathrm{SO}_{2} \mathrm{Me}$ (formed from $\mathrm{PCl}_{3}$ and MSA) were assumed to be the nucleophiles [10]. At the same time, applying sulfolane as the solvent, there was a need for at least 2 equivalents of both $\mathrm{PCl}_{3}$ and $\mathrm{P}(\mathrm{OH})_{3}$. In this case, $\mathrm{Cl}_{2} \mathrm{P}-\mathrm{O}-\mathrm{P}(\mathrm{OH})_{2}$ was found to be the nucleophile [10]. 

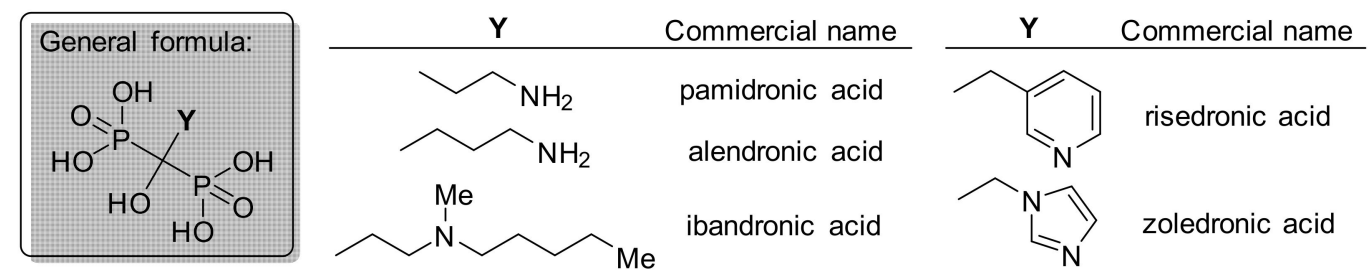

Figure 1. $N$-containing dronic acid derivatives.

Results of the synthesis of the most important dronic acid derivatives applying the above-mentioned methods ( $\mathrm{PCl}_{3} / \mathrm{MSA}$ or $\mathrm{PCl}_{3} / \mathrm{H}_{3} \mathrm{PO}_{3} /$ sulfolane) are summarized in Table 1. On the basis of the diverse yields of the two methods, it is not possible to judge which one is to be preferred. It was, however, unambiguous that using sulfolane, a 2:3 or 2:4 ratio of $\mathrm{PCl}_{3}$ and $\mathrm{P}(\mathrm{OH})_{3}$, was in most cases advantageous.

Table 1. Preparative results of more important dronic acid derivatives.

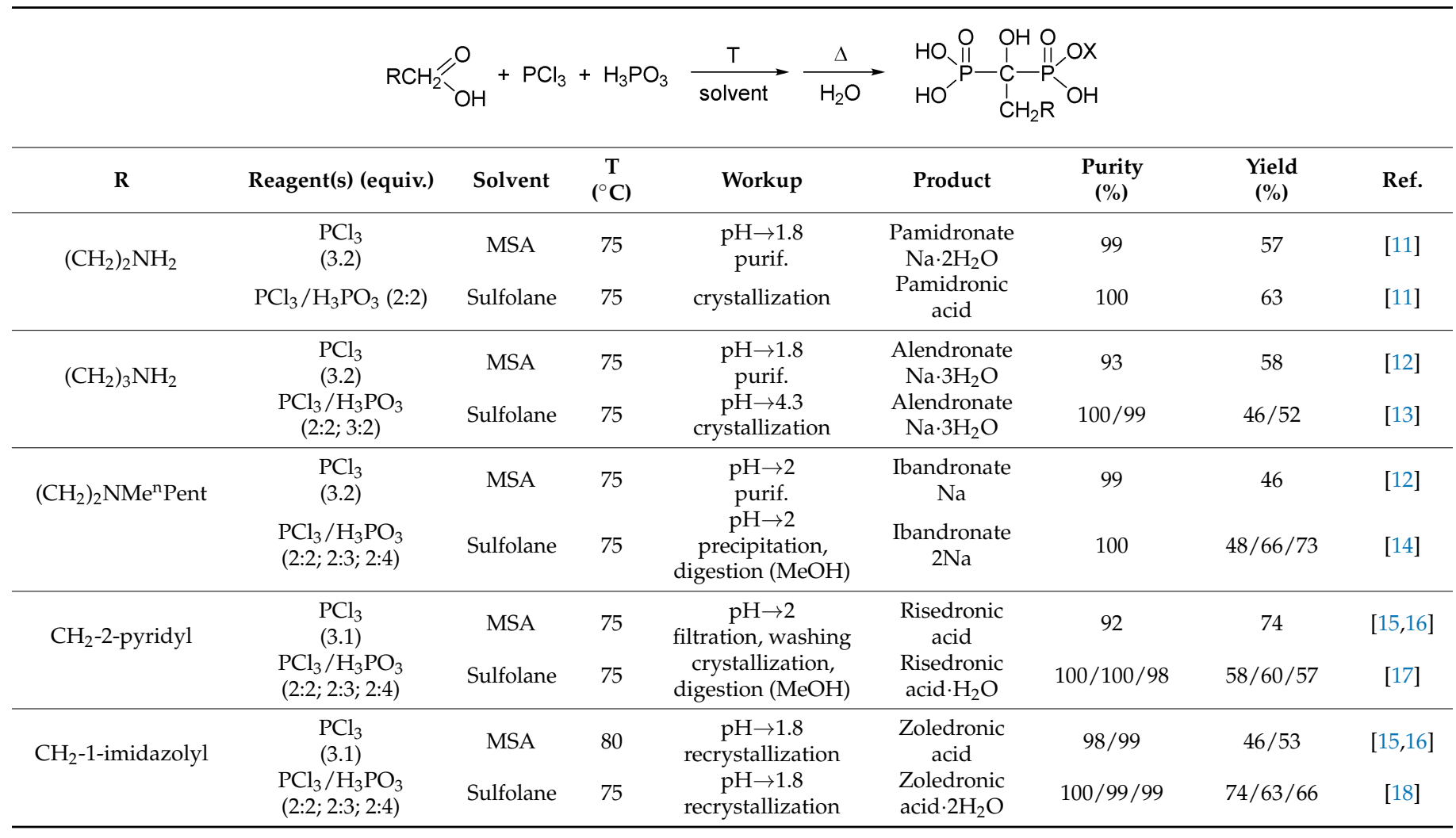

As, with a few exceptions, the preparative results of the two methods for the different dronic acid derivatives were not comparable due to unreliable experiments, we wished to evaluate the energetics of the dronate formation on simple models using quantum chemical calculations. The two models selected were the formation of fenidronate and benzidronate from benzoic acid and phenylacetic acid, respectively, or from their derivatives.

\section{Results and Discussion}

\subsection{A Study on the Formation of Fenidronic Acid}

To have a simple model for the calculations, the reaction of benzoic acid with $\mathrm{P}$ reagents was chosen. Version A involved the reaction with $\mathrm{PCl}_{3}$ in MSA. Preparative experiments showed that the reaction of benzoic acid with 3.2 equivalents of $\mathrm{PCl}_{3}$ in MSA at $75^{\circ} \mathrm{C} /$ day, followed by hydrolysis at $105^{\circ} \mathrm{C} / 4 \mathrm{~h}$, $\mathrm{pH}$ adjustment to 1.8 by $\mathrm{NaOH} / \mathrm{H}_{2} \mathrm{O}$, 
and precipitation with methanol afforded the disodium salt of fenidronic acid (fenidronate) in a $46 \%$ yield, in a pure form [19]. Version $\mathrm{B}$ for the theoretical study comprised the reaction of benzoic acid with $\mathrm{PCl}_{3}$ and $\mathrm{P}(\mathrm{OH})_{3}$ in sulfolane (Scheme 1).

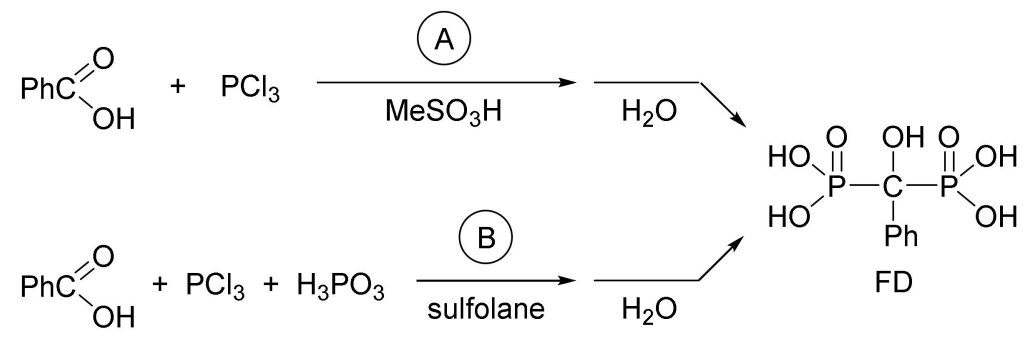

Scheme 1. Two models for the theoretical computations on fenidronic acid (FD).

Applying 3 equivalents of $\mathrm{PCl}_{3}$ in MSA, benzoic acid itself, benzoyl chloride formed from the benzoic acid, and the mixed anhydride formed from benzoic acid and methanesulfonyl chloride or from benzoyl chloride and MSA, under the conditions of the reaction may be regarded as the starting substrates undergoing addition of the P-nucleophile. The attacking P-reagents may be $\mathrm{PCl}_{3}$ itself and the $\mathrm{Cl}_{2} \mathrm{P}-\mathrm{O}-\mathrm{SO}_{2} \mathrm{Me}$ species formed from $\mathrm{PCl}_{3}$ and MSA. The variations outlined are summarized in Scheme 2. The anhydrides were assumed already in the earlier stage of our work [20]. We performed DFT-level computations at the M062X/6-311+G $(\mathrm{d}, \mathrm{p})$ level considering the solvent effect of water or DMSO simulating MSA and sulfolane, respectively, using the SMD solvent model with the Gaussian 09 program package. One can see that the most advantageous reaction variations were the ones starting from benzoyl chloride and $\mathrm{Cl}_{2} \mathrm{P}-\mathrm{O}-\mathrm{SO}_{2} \mathrm{Me}$ or $\mathrm{PCl}_{3}$ as the P-nucleophiles (for the best case, see the framed part of Scheme 2). In any other case, the transition states (TS1,2,5,6) required an energy investment of higher than $200 \mathrm{~kJ} \mathrm{~mol}^{-1}$ and these reactions were more endothermic. It is also noted that starting from all the three benzoic acid derivatives, irrespective of whether the nucleophile is $\mathrm{PCl}_{3}$ or $\mathrm{Cl}_{2} \mathrm{P}-\mathrm{O}-\mathrm{SO}_{2} \mathrm{Me}$, the intermediates contain a pentavalent pentacoordinated phosphorus atom. At the same time, the intermediate formed from benzoic acid or from the mixed anhydride is presumed to incorporate a three-membered oxaphosphirane ring.
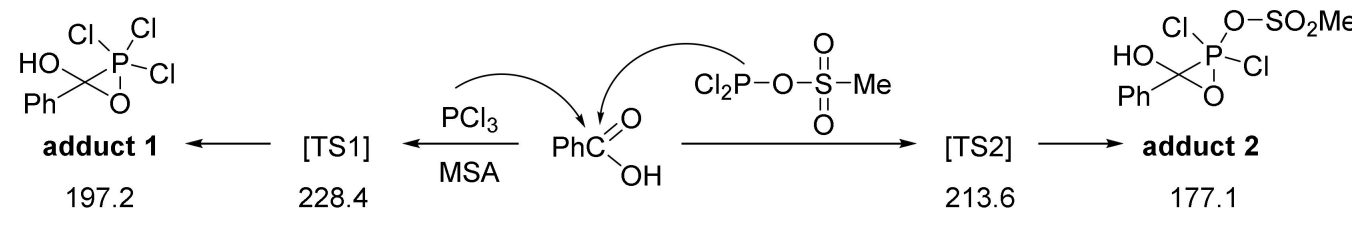

(Version A)<smiles>O=C([PH2+])[PH](Cl)(Cl)(Cl)(Cl)Cl</smiles>

adduct 3

115.5
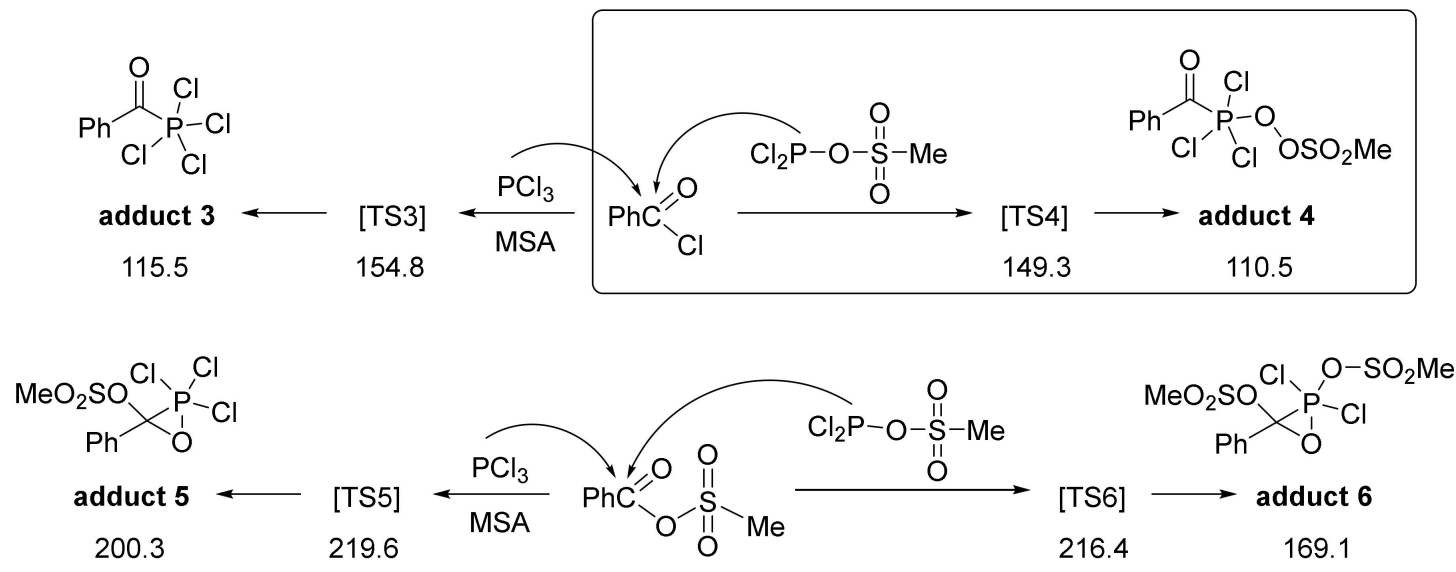

Scheme 2. Possible starting steps in the reaction of benzoic acid or its derivatives with $\mathrm{PCl}_{3}$ in $\mathrm{MSA}$ (the numbers below the TSs mean the corresponding Gibbs free energy of activation). 
For the formation of the bis adducts, we chose the energetically most favorable adduct 3 and adduct 4 as the starting intermediates. The protonation of these adducts 3 and 4 on the carbonyl oxygen seemed crucial, as without protonation, no reaction could be observed computationally. It was assumed that the MSA applied in large excess is responsible for the protonation. For the estimation of the protonation energy, we took the gas-phase Gibbs free energy of the proton [21] and took into account the computed Gibbs free energies of MSA and its conjugate base, methanesulfonate. The protonated intermediates ((adduct 3$)$ $+\mathrm{H}^{+}$and (adduct 4) $+\mathrm{H}^{+}$) were then reacted with $\mathrm{PCl}_{3}$ or with $\mathrm{Cl}_{2} \mathrm{P}-\mathrm{O}-\mathrm{SO}_{2} \mathrm{Me}$ (Scheme 3). The transition states (TS7-TS10) needed a further $85-98 \mathrm{~kJ} \mathrm{~mol}^{-1}$ energy investment, as compared to the energies of the protonated adducts, and the reactions were endothermic, leading to bis adducts 1-4. The reaction with the lowest activation energy (TS10) was the one between adduct 4 and $\mathrm{Cl}_{2} \mathrm{P}-\mathrm{O}-\mathrm{SO}_{2} \mathrm{Me}$, leading to bis adduct 4 (see the framed part of Scheme 3). Thereafter, the formation of fenidronic acid from bis adducts 1-4 was calculated. The elimination of $\mathrm{HCl}$ and/or MSA on the addition of water took place with an energy release of $-390-420 \mathrm{~kJ} \mathrm{~mol}^{-1}$. This means that the final hydrolysis is highly exothermic and might be the driving force for the whole reaction sequence. We have depicted the energetically most advantageous reaction pathway in Figure 2.<smiles>OC(c1ccccc1)([P+](Cl)(Cl)Cl)P(Cl)(Cl)(Cl)Cl</smiles>

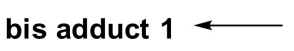

212.5<smiles>OC(Cl)(Cl)P(Cl)(Cl)(Cl)C(O)(Cl)[P+](Cl)(Cl)c1ccccc1</smiles>

[TS7]

240.5

[TS9]

229.9

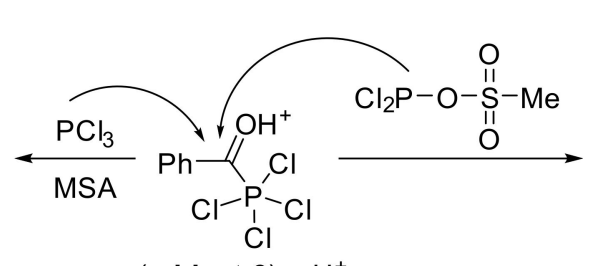

(adduct 3$)+\mathrm{H}^{+}$

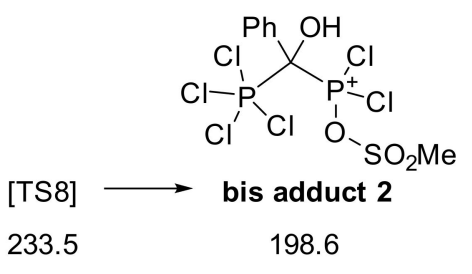

198.6

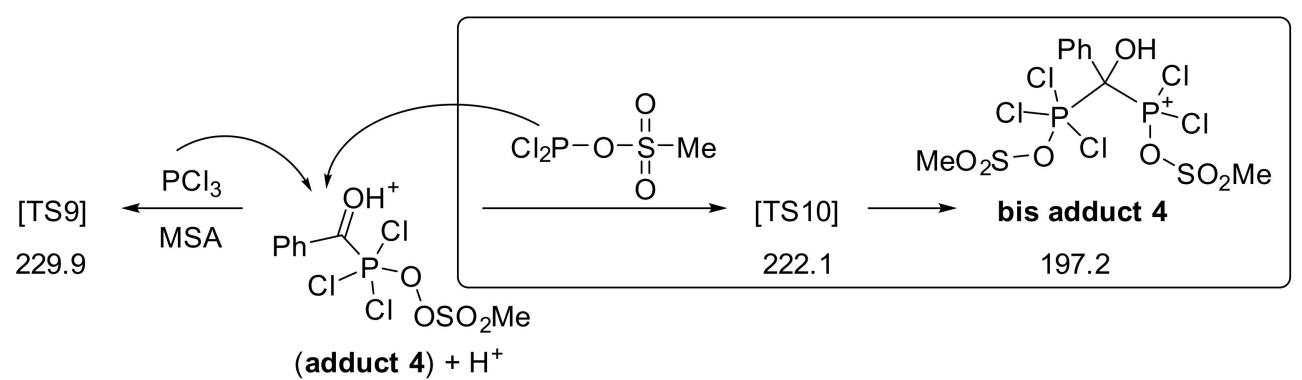

Scheme 3. Possible steps for the formation of bis adducts 1-4 (the numbers below the TSs mean the corresponding Gibbs free energy of activation).

The possible starting materials were assumed to be $2-2$ equivalents of $\mathrm{PCl}_{3}$ and $\mathrm{P}(\mathrm{OH})_{3}$ in sulfolane, benzoic acid, and benzoyl chloride. As regards the P-nucleophile, $\mathrm{Cl}_{2} \mathrm{P}-\mathrm{O}$ $\mathrm{P}(\mathrm{OH})_{2}$ formed from $\mathrm{PCl}_{3}$ and $\mathrm{P}(\mathrm{OH})_{3}$ was regarded as the active agent. At the same time, $(\mathrm{HO})_{2} \mathrm{P}-\mathrm{PCl}-\mathrm{P}(\mathrm{OH})_{2}$ could also be the nucleophile. Moreover, as 1 equivalent of $\mathrm{PCl}_{3}$ covers the formation of $\mathrm{PhC}(\mathrm{O}) \mathrm{Cl}$ from $\mathrm{PhC}(\mathrm{O}) \mathrm{OH}$, the involvement of the latter P-nucleophile is more probable. However, to simplify the situation, $\mathrm{Cl}_{2} \mathrm{P}-\mathrm{O}-\mathrm{P}(\mathrm{OH})_{2}$ was assumed in the calculations. A part of the possibilities mentioned can be seen in Scheme 4. The lowest Gibbs free energy belonged to the transition state of the reaction of benzoyl chloride and $\mathrm{Cl}_{2} \mathrm{P}-\mathrm{O}-\mathrm{P}(\mathrm{OH})_{2}$ (TS13), which resulted in the less endothermic adduct 9 among the adducts in the series (see the framed part of Scheme 4). Adduct 9 is formed by P-C addition and $\mathrm{HCl}$ elimination in one single step. On the departure of the $\mathrm{HCl}$ molecule from the reaction complex, the adduct is stabilized by further $-20.2 \mathrm{~kJ} \mathrm{~mol}^{-1}$. It is also seen that the $-\mathrm{P}(\mathrm{OH})_{2}$ moiety of the $\mathrm{Cl}_{2} \mathrm{P}-\mathrm{O}-\mathrm{P}(\mathrm{OH})_{2}$ species is more nucleophilic than the $-\mathrm{PCl}_{2}$ unit. 


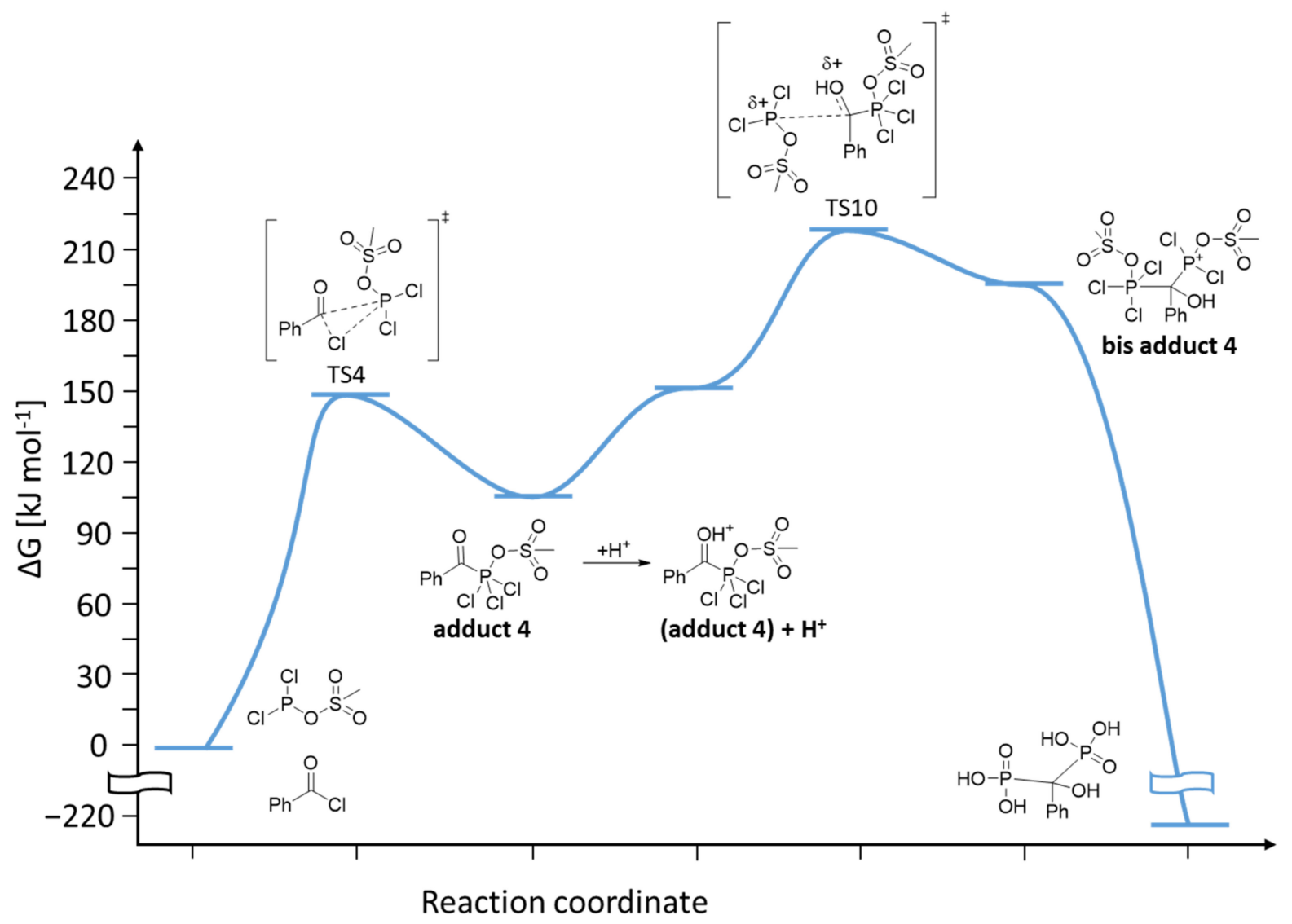

Figure 2. Gibbs free energy diagram for the formation of fenidronic acid from benzoyl chloride and $\mathrm{Cl}_{2} \mathrm{P}-\mathrm{O}-\mathrm{SO}_{2} \mathrm{Me}$.

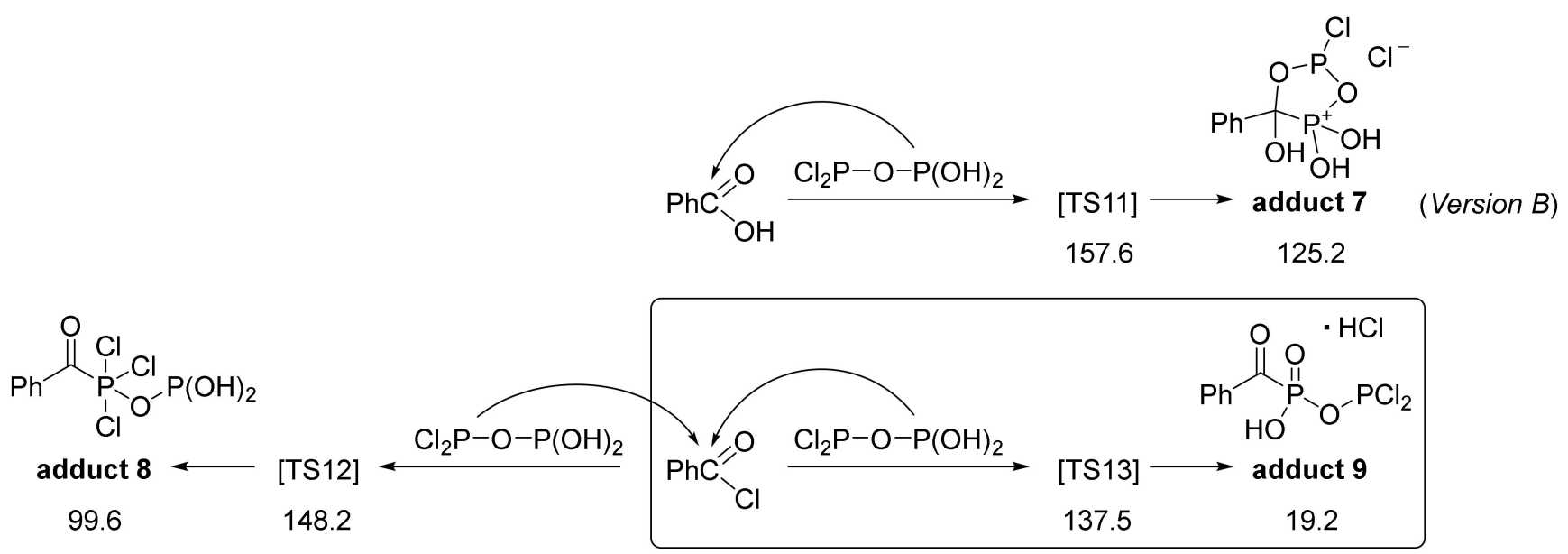

Scheme 4. Possible starting steps in the reaction of benzoic acid (or benzoyl chloride), $\mathrm{PCl}_{3}$, and $\mathrm{P}(\mathrm{OH})_{3}$ in sulfolane (the numbers below the TSs mean the corresponding Gibbs free energy of activation.).

The next adduct computed was formed from adduct 9 and a second molecule of $\mathrm{Cl}_{2} \mathrm{P}-\mathrm{O}-\mathrm{P}(\mathrm{OH})_{2}$. An important $\mathrm{P}-\mathrm{OH}-\mathrm{O}=\mathrm{P}$ hydrogen bridge was present in TS14, with an activation energy of $94.0 \mathrm{~kJ} \mathrm{~mol}^{-1}$, leading to bis adduct 5 in an exothermic reaction (Scheme 5). Again, the final step in this series was the exothermic hydrolysis. The energetically most advantageous reaction pathway is depicted in Figure 3. 


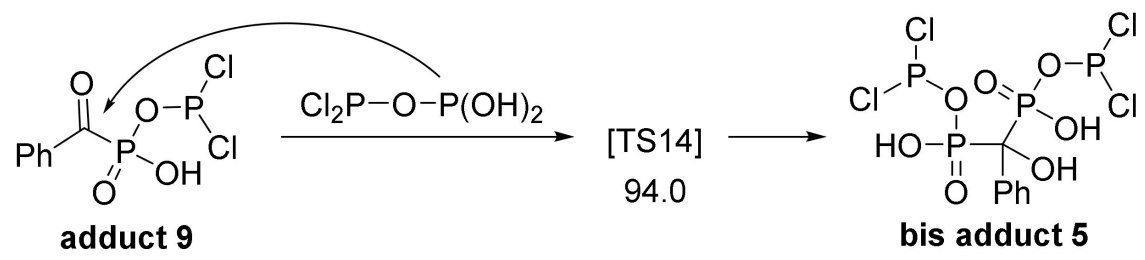

$-24.2$

Scheme 5. Possible bis adduct forming reaction (the numbers below the TSs mean the corresponding Gibbs free energy of activation).

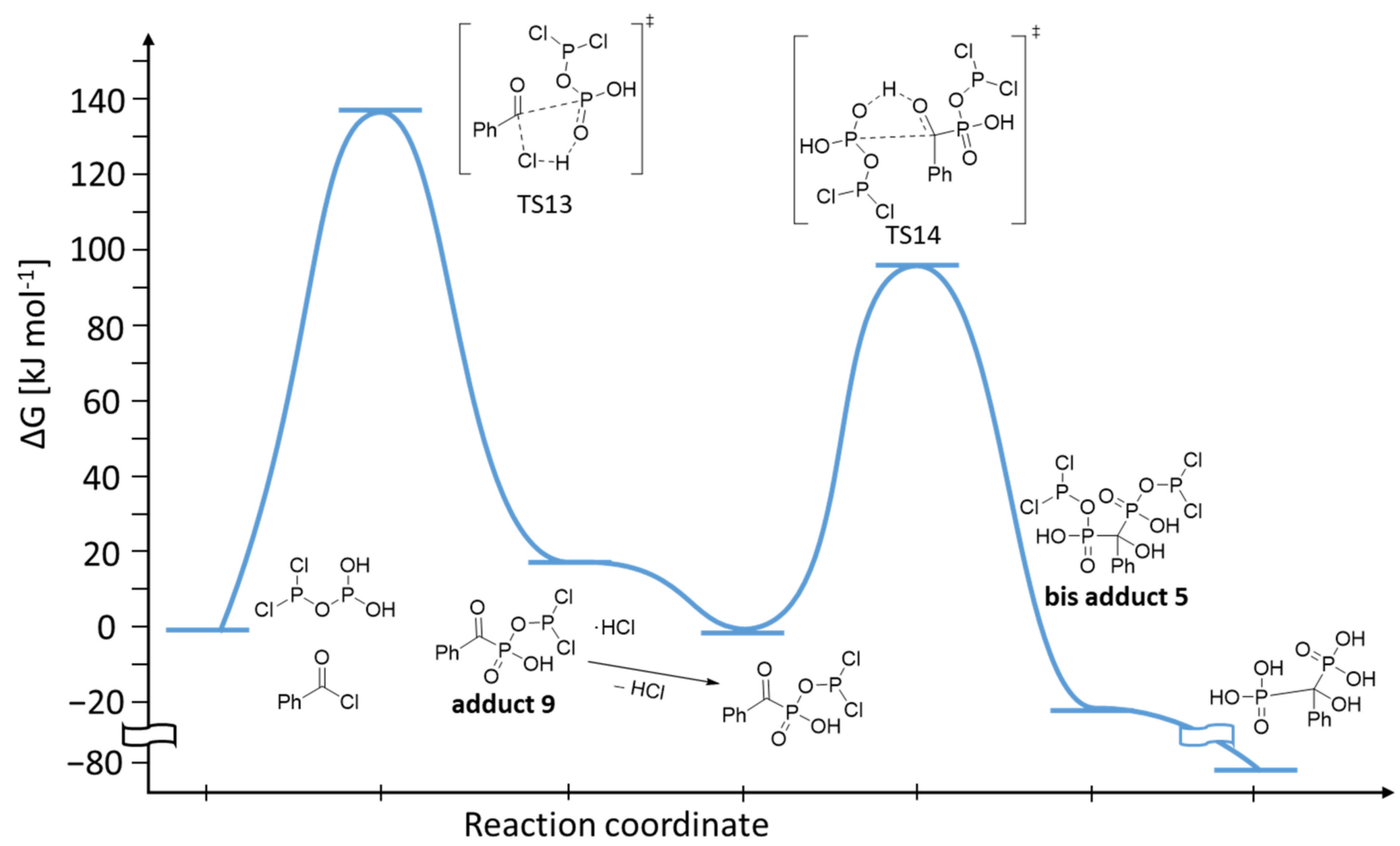

Figure 3. Gibbs free energy diagram for the formation of fenidronic acid from benzoyl chloride and $\mathrm{Cl}_{2} \mathrm{P}-\mathrm{O}-\mathrm{P}(\mathrm{OH})_{2}$.

\subsection{A Study on the Formation of Benzidronic Acid}

After investigating the formation of fenidronic acid, we turned our attention to benzidronic acid. The use of 2 equivalents of $\mathrm{PCl}_{3}$ gave benzidronate in a yield of $36 \%$ (Scheme 6). Further adding 1 equivalent of $\mathrm{H}_{3} \mathrm{PO}_{3}$, the yield increased to $74 \%$. Applying 3.2 equivalents $\mathrm{PCl}_{3}$ led to a yield of $46 \%$. When there was also 1 equivalent of $\mathrm{H}_{3} \mathrm{PO}_{3}$, the yield was $81 \%$ [22]. The positive effect of $\mathrm{H}_{3} \mathrm{PO}_{3}$ was surprising. The formation of the $(\mathrm{HO})_{2} \mathrm{P}-\mathrm{O}-\mathrm{PCl}_{2}$ intermediate must be assumed. In MSA as the solvent, there is only a slight chance that $\mathrm{PCl}_{3}$ will react with $\mathrm{H}_{3} \mathrm{PO}_{3}$ to provide $(\mathrm{HO})_{2} \mathrm{P}-\mathrm{O}-\mathrm{PCl}_{2}$, as due to the excess of MSA, the probability of the formation of $\mathrm{MeSO}_{2}-\mathrm{O}-\mathrm{PCl}_{2}$ is greater. However, the phenylacetyl derivatives may be more capable of reacting with $(\mathrm{HO})_{2} \mathrm{P}-\mathrm{O}-\mathrm{PCl}_{2}$ present only in a low concentration. 


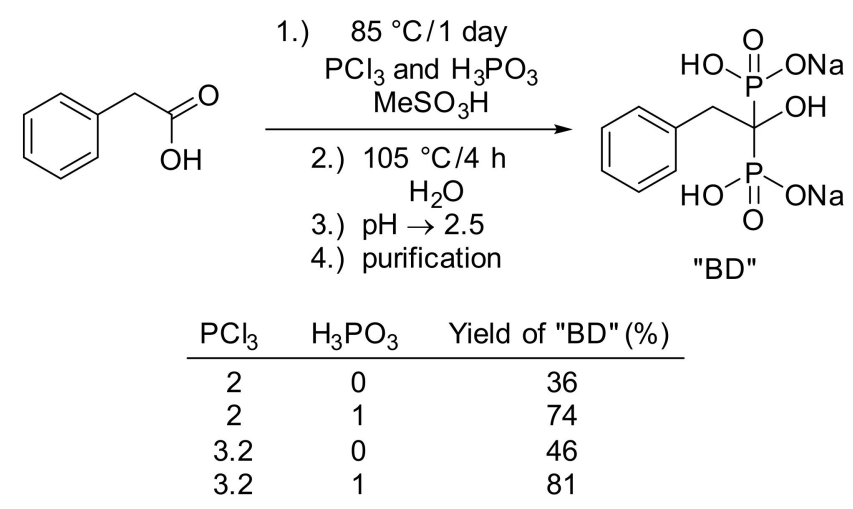

Scheme 6. Preparative results for the synthesis of benzidronate (BD) [17].

During the calculations, we took into consideration phenylacetyl chloride as the starting component reacting with $\mathrm{PCl}_{3}$ or with $\mathrm{Cl}_{2} \mathrm{P}-\mathrm{O}-\mathrm{O}_{2} \mathrm{SMe}$ in MSA (Scheme 7). The transition states (TS15 and TS16) were of 116.1 and $134.7 \mathrm{~kJ} \mathrm{~mol}^{-1}$, respectively. The values were similarly low as in the reaction with benzoyl chloride, although in this case, the route involving $\mathrm{PCl}_{3}$ was the more favorable option (see the framed part of Scheme 7).

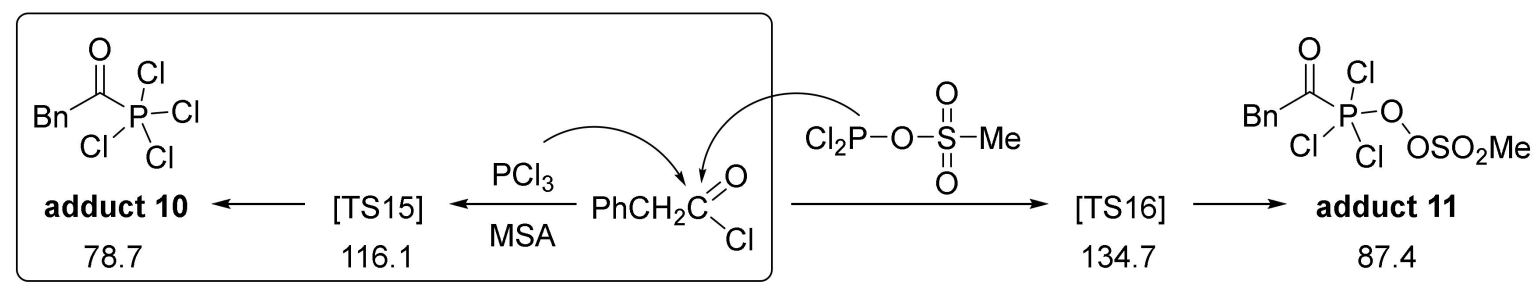

Scheme 7. Possible starting steps in the reaction of phenylacetyl chloride and $\mathrm{PCl}_{3}$ in MSA (the numbers below the TSs mean the corresponding Gibbs free energy of activation).

Both energetically similar pathways were calculated further. The protonation and formation of the corresponding bis adducts from adducts $\mathbf{1 0}$ and $\mathbf{1 1}$ was computed assuming both $\mathrm{PCl}_{3}$ and $\mathrm{Cl}_{2} \mathrm{P}-\mathrm{O}-\mathrm{O}_{2} \mathrm{SMe}$ as the nucleophiles (Scheme 8 ). Transition states TS17-TS20 required less (54-71 $\mathrm{kJ} \mathrm{mol}^{-1}$ ) further energy investment than those in the analogous steps of fenidronic acid formation, and bis adducts 6-9 had much lower energy levels (between 115 and $165 \mathrm{~kJ} \mathrm{~mol}^{-1}$ ) as compared to the range of 193-212 $\mathrm{kJ} \mathrm{mol}^{-1}$ obtained for bis adducts 1-4 (Scheme 3 ). In this case, again $\mathrm{PCl}_{3}$ was the most favorable reagent (see the framed part of Scheme 8). Notably, taking a look over the energy value of the final dronic acids, one may conclude that the last hydrolysis is again a highly exothermic step $\left(-390-420 \mathrm{~kJ} \mathrm{~mol}^{-1}\right)$. We have depicted the most advantageous reaction pathway in Figure 4.

In the case of the other reaction setup with sulfolane as the solvent, phenylacetyl chloride was reacted with $\mathrm{Cl}_{2} \mathrm{P}-\mathrm{O}-\mathrm{P}(\mathrm{OH})_{2}$ (Scheme 9). The activation energy required for the first and second additions (TS21 and TS22) were lower for both cases than that for the reaction with benzoyl chloride (TS13 and TS14) $\left(75.0 \mathrm{vs.} 137.5 \mathrm{~kJ} \mathrm{~mol}^{-1}\right.$ and 52.8 vs. $94.0 \mathrm{~kJ} \mathrm{~mol}^{-1}$ ), and both steps were found to be exothermic. The $\mathrm{HCl}$ elimination in this case led to an energy gain of $-43.9 \mathrm{~kJ} \mathrm{~mol}^{-1}$. The final hydrolysis was again highly exothermic. We have shown the plausible reaction pathway in Figure 5. 


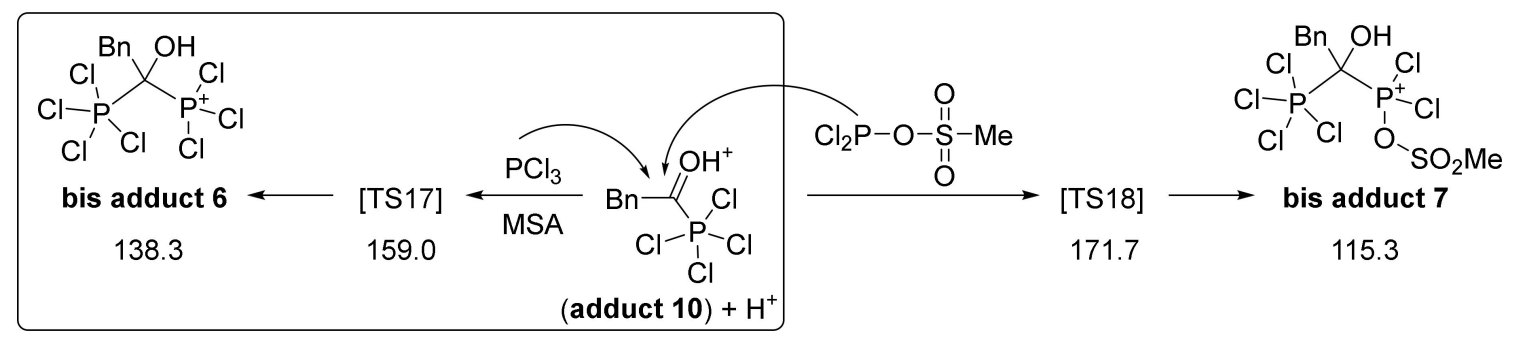

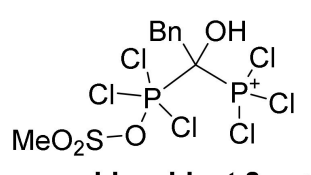

bis adduct 8

165.4

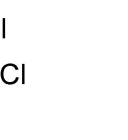

[TS19]

184.2

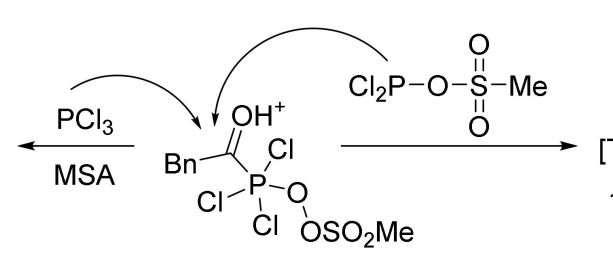

(adduct 11) $+\mathrm{H}^{+}$

Scheme 8. Possible steps for the formation of bis adducts 6-9 (the numbers below the TSs mean the corresponding Gibbs free energy of activation).

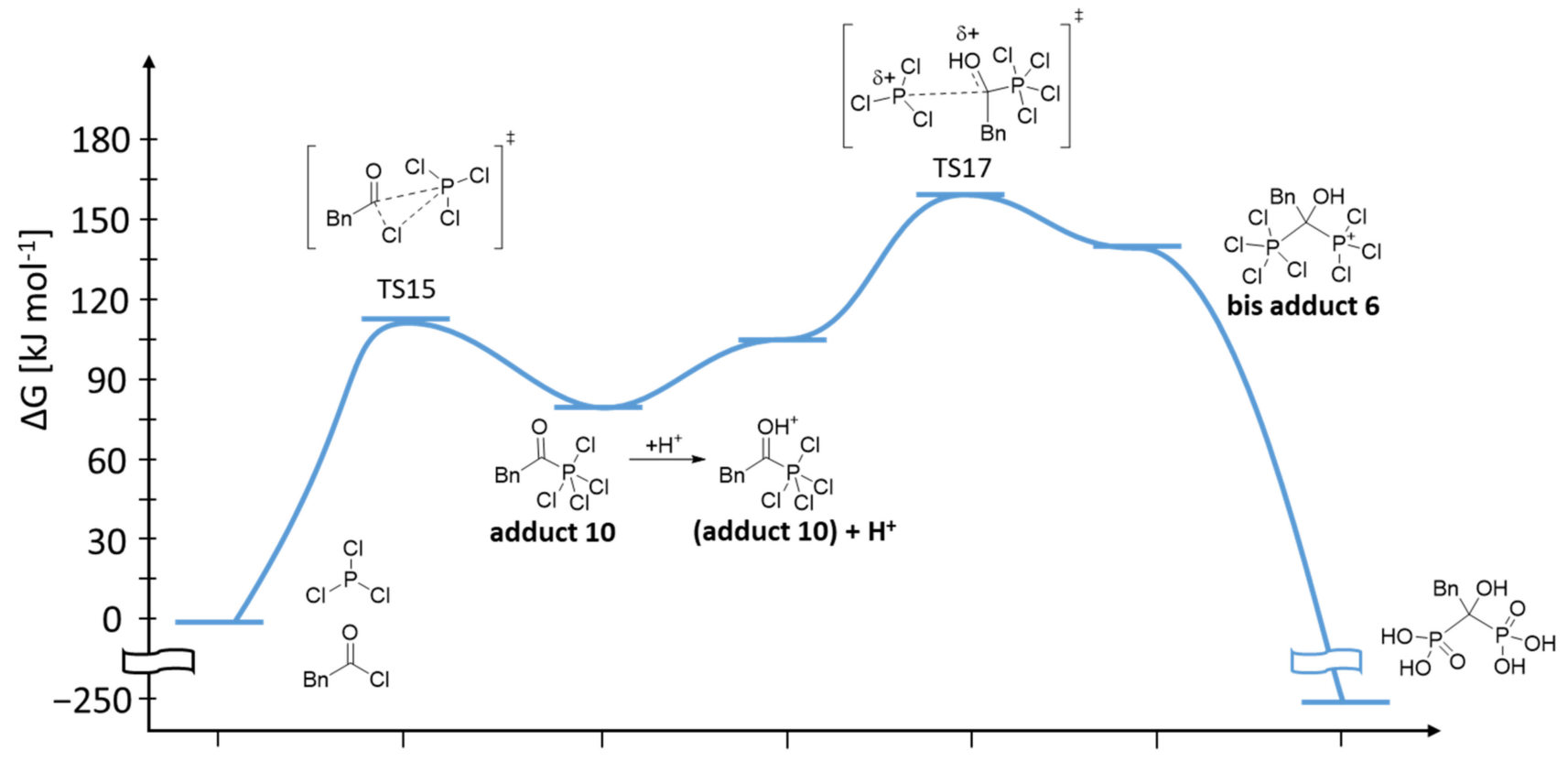

\section{Reaction coordinate}

Figure 4. Gibbs free energy diagram for the formation of benzidronic acid from phenylacetyl chloride and $\mathrm{PCl}_{3}$.
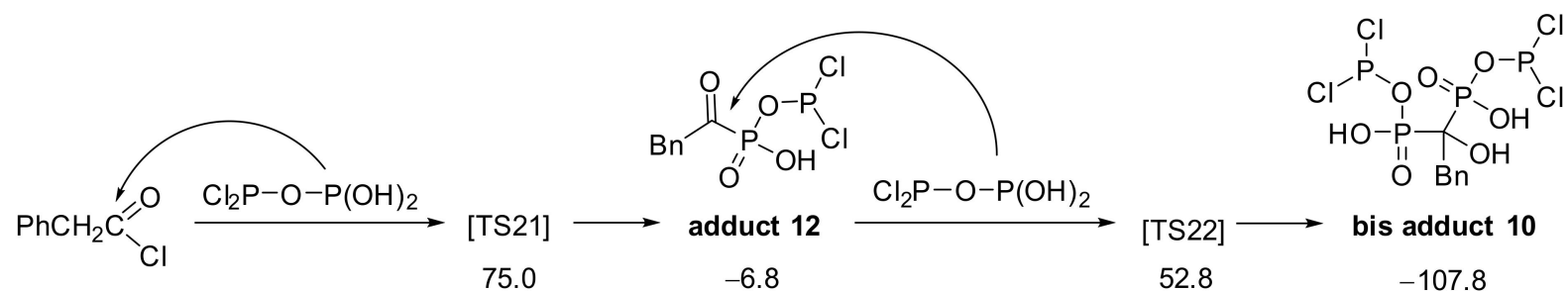

75.0

$-6.8$

[TS22]

bis adduct 10

52.8

$-107.8$

Scheme 9. Possible steps for the formation of bis adduct 10 (the numbers below the TSs mean the corresponding Gibbs free energy of activation). 
The reported yields for benzidronate, in general, were higher than those for fenidronate, which is in accord with the results of the computations suggesting lower activation Gibbs free energies for the formation of benzidronate and steps that are more exothermic before the final hydrolysis. Moreover, in the case of benzidronate, the improving effect of $\mathrm{H}_{3} \mathrm{PO}_{3}$ was shown experimentally, suggesting that the formation of the $\mathrm{Cl}_{2} \mathrm{P}-\mathrm{O}-\mathrm{P}(\mathrm{OH})_{2}$ reactant is realistic, and results in increased yields. This is also supported by the lower activation energy in the reaction with $\mathrm{Cl}_{2} \mathrm{P}-\mathrm{O}-\mathrm{P}(\mathrm{OH})_{2}$ as compared to the case with $\mathrm{Cl}_{2} \mathrm{P}-\mathrm{O}-\mathrm{O}_{2} \mathrm{SMe}$ as the nucleophile. Notably, in all cases, the acyl chloride was suggested to be the most favorable reactant, implying that the carboxylic acid, in the first step, is transformed by $\mathrm{PCl}_{3}$ to the corresponding chloride.

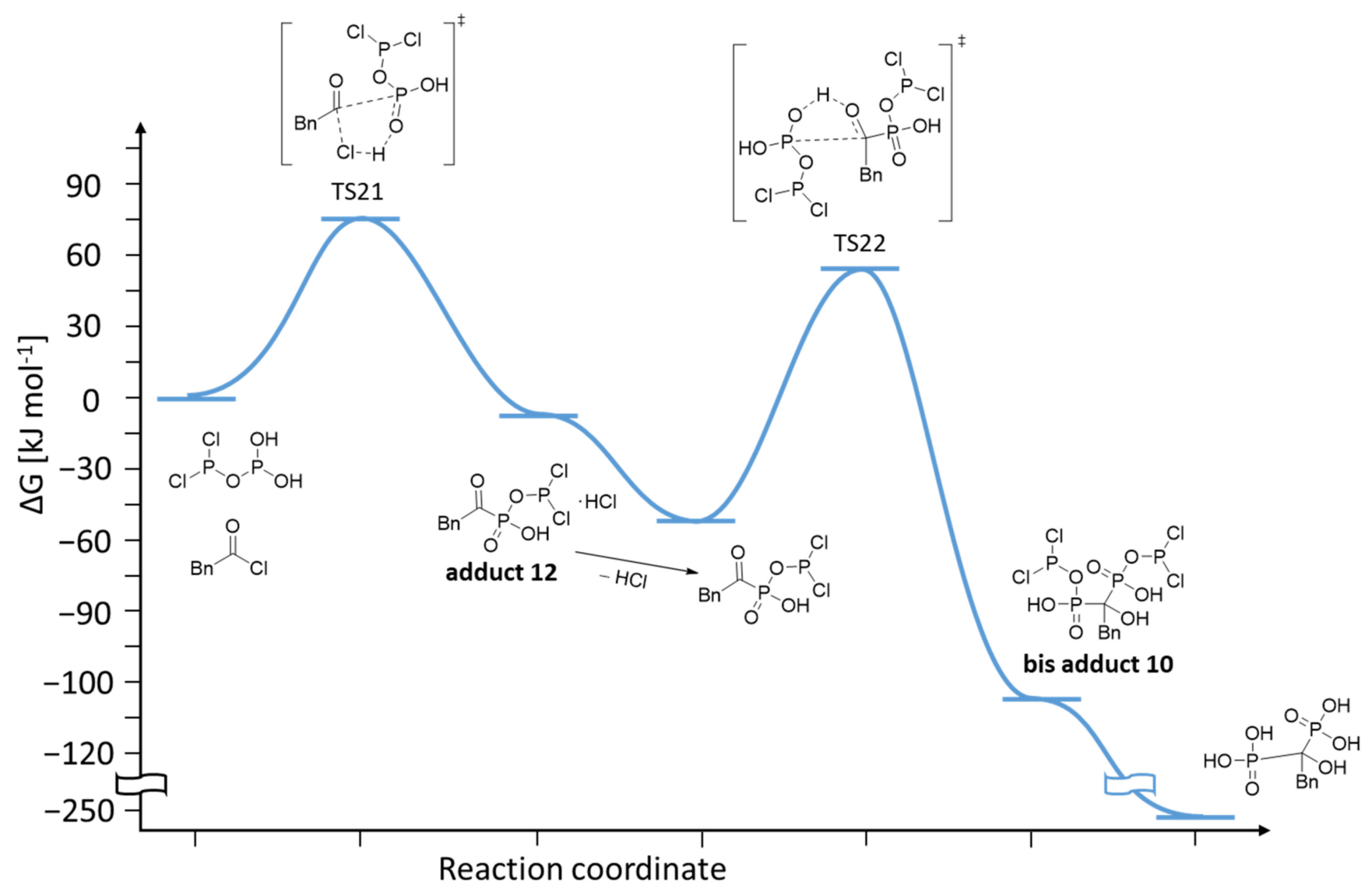

Figure 5. Gibbs free energy diagram for the formation of benzidronic acid from phenylacetyl chloride and $\mathrm{Cl}{ }_{2} \mathrm{P}-\mathrm{O}-\mathrm{P}(\mathrm{OH})_{2}$.

\section{Conclusions}

The possible mechanistic pathways leading to fenidronic acid and benzidronic acid were computed considering the reaction of benzoic acid or phenylacetic acid and derivatives with $\mathrm{PCl}_{3}$ in MSA or with $\mathrm{PCl}_{3} / \mathrm{P}(\mathrm{OH})_{3}$ in sulfolane. It was found that the corresponding acyl chlorides should be considered as the starting compounds and $\mathrm{PCl}_{3}$ or its condensed derivative with MSA or $\mathrm{H}_{3} \mathrm{PO}_{4}\left(\mathrm{Cl}_{2} \mathrm{P}-\mathrm{O}-\mathrm{SO}_{2} \mathrm{Me}\right.$ or $\mathrm{Cl}_{2} \mathrm{P}-\mathrm{O}-\mathrm{P}(\mathrm{OH})_{2}$, respectively) may be the nucleophile. The multistep formation of the bis adducts was in most cases endothermic, and the exothermic final hydrolyses could be the driving force for the series of reactions. In the case of benzidronic acid, the activation Gibbs free energies were lower for all steps than that for fenidronic acid. It is noteworthy that in the case of using $\mathrm{PCl}_{3} / \mathrm{P}(\mathrm{OH})_{3}$ in sulfolane, the formation of the adducts was exothermic. It unambiguously turned out that the setup with $\mathrm{PCl}_{3} / \mathrm{P}(\mathrm{OH})_{3}$ in sulfolane involving $(\mathrm{HO})_{2} \mathrm{P}-\mathrm{O}-\mathrm{PCl}_{2}$ as the nucleophile is the energetically more preferable option. Hence, regarding the synthesis of dronic acid derivatives, the $\mathrm{PCl}_{3} / \mathrm{P}(\mathrm{OH})_{3} /$ sulfolane method is recommended. 


\section{Computational Protocol}

DFT-level computations at the M062X/6-311+G $(\mathrm{d}, \mathrm{p})$ level were performed considering the solvent effect of water $(\varepsilon=78.4)$ or DMSO $(\varepsilon=46.8)$ simulating MSA (no $\varepsilon$ is available. However, the physical properties of MSA are similar to that of sulfuric acid $\left.\left(\varepsilon_{\mathrm{H} 2 \mathrm{SO} 4}=84\right)[23,24]\right)$ and sulfolane $(\varepsilon=43.4)[25]$ on using the SMD solvent model with the Gaussian 09 program package. The actual solvents were chosen based on their similar dielectric constants. The popular M062x method was chosen for its known accuracy for main group thermochemistry and the computation of barrier heights [26]. The geometries of the molecules were optimized in all cases (see Supplementary Material), and frequency calculations were also performed to assure that the structures are in a local minimum or in a saddle point. This was followed by single-point measurements at the M062X/6-311++G (3df,3pd) level, which resulted in the energy values presented in Table S1 and used for the figures of the manuscript. The solution-phase Gibbs free energies were obtained by frequency calculations as well. The $G$ values obtained were given under standard conditions, and the corrected total energies of the molecules were taken into account. Entropic and thermal corrections were evaluated for isolated molecules using standard rigid rotor harmonic oscillator approximations. That is, the Gibbs free energy was taken as the "sum of electronic and thermal free energies" printed in a Gaussian 09 vibrational frequency calculation. Standard state correction was taken into account. The transition states were optimized with the QST3 or the TS (Berny) method. Transition states were identified by having one imaginary frequency in the Hessian matrix and connecting two corresponding minima.

Supplementary Materials: The best preparative procedures, together with compound characterization; details of theoretical calculations: Table S1: X, Y, Z Coordinates of the computed structures (columns are in this order), Table S2: Energy (Hartree) and entropy (cal molK-1) values obtained for the computations together with imaginary 2150 frequencies $(1 / \mathrm{s})$.

Author Contributions: P.Á-B. performed the calculations, performed data processing, evaluated the results, and wrote the manuscript; I.G. acquired the project, performed literature survey, and performed critical evaluation of the results; G.K. raised the funds, managed the project, supervised and planned the project, and wrote the manuscript. All authors have read and agreed to the published version of the manuscript.

Funding: This project was supported by the National Research, Development and Innovation Office (K134318) and János Bolyai Research Scholarship of the Hungarian Academy of Sciences for P.Á-B.

Institutional Review Board Statement: Not applicable.

Informed Consent Statement: Not applicable.

Data Availability Statement: Not applicable.

Conflicts of Interest: The authors declare no conflict of interest.

Sample Availability: Samples of the compounds are available from the authors.

\section{References}

1. Russell, R.G.G. Bisphosphonates: The first 40 years. Bone 2011, 49, 2-19. [CrossRef] [PubMed]

2. Hudson, H.R.; Wardle, N.J; Blight, S.W.A.; Greiner, I.; Grün, A.; Keglevich, G. N-heterocyclic dronic acids; applications and synthesis. Mini Rev. Med. Chem. 2012, 12, 313-325. [CrossRef] [PubMed]

3. Rogers, M.J.; Gordon, S.; Benford, H.L.; Coxon, F.P.; Luckman, S.P.; Monkkonen, J.; Frith, J.C. Cellular and molecular mechanisms of action of bisphosphonates. Cancer 2000, 88, 2961-2978. [CrossRef]

4. Nagy, D.I.; Grün, A.; Garadnay, S.; Greiner, I.; Keglevich, G. Synthesis of hydroxymethylenebisphosphonic acid derivatives in different solvents. Molecules 2016, 21, 1046. [CrossRef] [PubMed]

5. Coukell, A.J;; Markham, A. Pamidronate. A review of its use in the management of osteolytic bone metastases, tumour-induced hypercalcaemia and Paget's disease of bone. Drugs Aging 1998, 12, 149-168. [CrossRef] [PubMed]

6. Sharpe, M.; Noble, S.; Spencer, C.M. Alendronate: An update of its use in osteoporosis. Drugs 2001, 61, 999-1039. [CrossRef] [PubMed]

7. Chesnut, C.H. Treating osteoporosis with bisphosphonates and addressing adherence: A review of oral ibandronate. Drugs 2006, 66, 1351-1359. [CrossRef] 
8. Dunn, C.J.; Goa, K.L. Risedronate: A review of its pharmacological properties and clinical use in resorptive bone disease. Drugs 2001, 61, 685-712. [CrossRef]

9. Cheer, S.M.; Noble, S. Zoledronic acid. Drugs 2001, 61, 799-805. [CrossRef]

10. Nagy, D.I.; Grün, A.; Greiner, I.; Keglevich, G. The role of phosphorus trichloride and phoshorous acid in the formation of $\alpha$-hydroxymethylenebisphosphonic acids from the corresponding carboxylic acids-A mechanistic overview. Curr. Org. Chem. 2017, 21, 1567-1578. [CrossRef]

11. Kovács, R.; Grün, A.; Németh, O.; Garadnay, S.; Greiner, I.; Keglevich, G. The synthesis of pamidronic derivatives in different solvents: An optimization and a mechanistic study. Heteroat. Chem. 2014, 25, 186-193. [CrossRef]

12. Kovács, R.; Grün, A.; Garadnay, S.; Greiner, I.; Keglevich, G. Rational synthesis of ibandronate and alendronate. Curr. Org. Synth 2013, 10, 640-644. [CrossRef]

13. Nagy, D.I.; Grün, A.; Garadnay, S.; Greiner, I.; Keglevich, G. Investigation of the effect of medium in the preparation of alendronate: Till now the best synthesis in the presence of an ionic liquid additive. Heteroat. Chem. 2017, 28, e21370. [CrossRef]

14. Nagy, D.I.; Grün, A.; Pavela, O.; Garadnay, S.; Greiner, I.; Keglevich, G. Efficient synthesis of ibandronate in the presence of an ionic liquid. Lett. Drug Des. Discov. 2018, 15, 713-720. [CrossRef]

15. Garadnay, S.; Grün, A.; Keglevich, G.; Neu, J. Novel process for the preparation of dronic acids. Chem. Abstr. 2012, 157, 356874.

16. Keglevich, G.; Grün, A.; Aradi, K.; Garadnay, S.; Greiner, I. Optimized synthesis of N-heterocyclic dronic acids; closing a black-box era. Tetrahedron Lett. 2011, 52, 2744-2746. [CrossRef]

17. Nagy, D.I.; Grün, A.; Sinkovicz, J.; Garadnay, S.; Greiner, I.; Keglevich, G. A study on the synthesis of risedronic acid; The role of ionic liquid additive. Lett. Drug Des. Discov. 2019, 16, 238-244. [CrossRef]

18. Nagy, D.I.; Grün, A.; Lévay, K.; Garadnay, S.; Greiner, I.; Keglevich, G. Efficient syntheses of zoledronic acid as an active ingredient of a drug against osteoporosis. Synth. Commun. 2018, 48, 663-671. [CrossRef]

19. Grün, A.; Kovács, R.; Nagy, D.I.; Garadnay, S.; Greiner, I.; Keglevich, G. The rational synthesis of Fenidronate. Lett. Org. Chem. 2014, 11, 368-373. [CrossRef]

20. Keglevich, G.; Grün, A.; Kovács, R.; Koós, K.; Szolnoki, B.; Garadnay, S.; Neu, J.; Drahos, L.; Greiner, I. Heteroacetyl Chlorides and mixed anhydrides as intermediates in the synthesis of heterocyclic dronic acids. Lett. Drug Des. Discov. 2012, 9, 345-351. [CrossRef]

21. Fifen, J.J.; Dhaouadi, Z.; Nsango, M. Revision of the thermodynamics of the proton in gas phase. J. Phys. Chem. A 2014, 118, 11090-11097. [CrossRef]

22. Grün, A.; Kovács, R.; Nagy, D.I.; Garadnay, S.; Greiner, I.; Keglevich, G. Efficient synthesis of benzidronate applying of phosphorus trichloride and phosphorous acid. Lett. Drug Des. Discov. 2015, 12, 78-84. [CrossRef]

23. Engineering ToolBox. Relative Permittivity-The Dielectric Constant. 2010. Available online: https://www.engineeringtoolbox. com/relative-permittivity-d_1660.html (accessed on 8 December 2021).

24. Wickleder, M.S.; Logemann, C. Comprehensive Inorganic Chemistry II, Chapter 2.18.4.3.3, 2nd ed.; Reedijk, J., Poeppelmeier, K., Eds.; Elsevier: Amsterdam, The Netherlands, 2013; pp. 491-509. [CrossRef]

25. Tilstam, U. Sulfolane: A versatile dipolar aprotic solvent. Org. Process Res. Dev. 2012, 16, 1273-1278. [CrossRef]

26. Mardirossian, N.; Head-Gordon, M. Thirty years of density functional theory in computational chemistry: An overview and extensive assessment of 200 density functionals. Mol. Phys. 2017, 115, 2315-2372. [CrossRef] 